\title{
Variability in herbivore-induced defence signalling across different maize genotypes impacts significantly on natural enemy foraging behaviour
}

\author{
Mirian F. F. Michereff ${ }^{1}$. Diego M. Magalhães ${ }^{1} \cdot$ Marla J. Hassemer $^{1,2} \cdot$ Raúl A. Laumann $^{1} \cdot$ Jing-Jiang Zhou ${ }^{3}$. \\ Paulo E. de A. Ribeiro ${ }^{4}$ Paulo A. Viana ${ }^{4}$. Paulo E. de O. Guimarães ${ }^{4}$. Pedro H. C. Schimmelpfeng ${ }^{1} \cdot$ Miguel Borges $^{1}$. \\ John A. Pickett ${ }^{5}$. Michael A. Birkett ${ }^{3}$. Maria Carolina Blassioli-Moraes ${ }^{1}$ (D)
}

Received: 18 April 2018 / Revised: 22 June 2018 / Accepted: 4 August 2018 / Published online: 10 August 2018

(c) Springer-Verlag GmbH Germany, part of Springer Nature 2018

\begin{abstract}
'Smart' plants that release volatile defence compounds in response to pest damage, and which recruit beneficial natural enemies, offer an opportunity for exploiting biological control in future crop protection strategies. Using six maize genotypes, Zapalote Chico ('landrace'), Mirt2A, Sintético Spodoptera (SS), L3, and two commercial hybrids BRS 4103 and BRS 1040, the aim of this work was to evaluate maize responses to larval damage from the fall armyworm Spodoptera frugiperda, a major maize pest in Brazil, and the ability of the egg parasitoid Telenomus remus to respond to HIPVs induced by $S$. frugiperda damage. Y-tube olfactometer bioassays with $T$. remus showed preferential responses to the $S$. frugiperda-induced volatiles of SS and BRS 4103 compared to constitutive volatiles of the same genotypes, but to none of the other genotypes tested. Chemical analysis of maize volatile extracts showed that SS produced more volatile compounds in response to $S$. frugiperda damage, followed by BRS 4103. In addition, higher levels of mono, homo-, or sesquiterpenes, together with green leaf volatiles (GLVs) were the most attractive blend for T. remus; however, there was no attraction when only GLVs were produced in higher levels. In summary, these results show that volatile defence signalling produced by maize plants due to $S$. frugiperda damage varies significantly depending on maize genotype and this variability influences $T$. remus foraging behaviour.
\end{abstract}

Keywords Induced compounds $\cdot$ Indirect defence $\cdot$ Searching behaviour

Communicated by I. Hiltpold.

Electronic supplementary material The online version of this article (https://doi.org/10.1007/s10340-018-1033-6) contains supplementary material, which is available to authorized users.

Maria Carolina Blassioli-Moraes

carolina.blassioli@embrapa.br

1 Semiochemicals Laboratory, Embrapa Genetic Resources and Biotechnology, Brasília, DF, CEP 70770 - 917, Brazil

2 Department of Zoology, Institute of Biological Sciences, University of Brasília, Brasília, DF, Brazil

3 Rothamsted Research, Harpenden, Hertfordshire AL5 2JQ, UK

4 Entomology Laboratory, Embrapa Maize and Sorghum, Sete Lagoas, MG, Brazil

5 School of Chemistry, Cardiff University, Cardiff CF10 3AT, UK

\section{Key message}

- Six maize genotypes showed qualitative and quantitative differences in volatile defence signalling upon damage by the fall armyworm, Spodoptera frugiperda. Two genotypes produced higher amounts of mono-, homo-, and sesquiterpenes, in response to $S$. frugiperda damage.

- The differences in volatile defence signal production by the maize genotypes resulted in a genotype-specific response from the egg parasitoid, Telenomus remus. Volatile blends containing higher levels of monoterpenes combined with higher levels of homo- and/or sesquiterpenes, and GLVs appear to be related to T. remus attraction. 


\section{Introduction}

Maize, Zea mays L. (Poaceae), is one of the most important cultivated plants worldwide (Ranum et al. 2014; Galvão et al. 2014). During 2016/2017, the maize-planted area in Brazil occupied approximately 17 million hectares, and 97 million tonnes of corn was produced, of which 28 million tonnes was exported (CONAB 2017). Maize is attacked by a complex of pests, with the fall armyworm, Spodoptera frugiperda J.E. Smith, 1797 (Lepidoptera: Noctuidae), being considered as the primary pest in Brazil (Cruz et al. 2012). S. frugiperda attacks at all stages of maize development, but prefers seedlings, causing severe damage with losses reaching up to 100\% (Cruz 1995; Cruz et al. 2012). S. frugiperda is a polyphagous herbivore that is widespread in the Americas and which is now spreading across Africa, due to favourable climatic conditions and plenty of available food (Cruz 1995; Cruz et al. 2010; Midega et al. 2018). Despite the intensive use of insecticides to manage this pest, populations in maize crops have increased (Toscano et al. 2012), resulting in the use of additional pesticide applications and the development of insecticide resistance. Although Bt maize has contributed to a significant reduction of pest populations after its adoption over a span of 9 years in Brazil (Farias et al. 2014), this technology is still not accessible to smallholder and family farms due to its high cost. In addition, several studies have reported that $\mathrm{Bt}$ maize no longer controls fall armyworm populations in several regions of the country (Farias et al. 2014; Bernardi et al. 2015). In view of these growing threats to maize production, new interventions for $S$. frugiperda management in Brazil are urgently required.

Recently, it was proposed that sustainable intensification of agricultural systems requires the delivery of new crop protection tools via seed, i.e. GM, and the enhancement of ecosystem services, i.e. beneficial natural enemies from land set aside as natural habitats (Pickett and Khan 2016). New crop protection interventions might be based on chemical ecology, specifically through plant defence signalling, which can deliver crop protection using 'smart' plants, sentinel technology, and recruitment of ecosystem services (Pickett and Khan 2016). These technologies, in general, have low costs and are accessible for smallholder and industrial farming. The pioneering work on push-pull systems by the International Centre of Insect Physiology and Ecology (icipe), for cereal production in sub-Saharan Africa, has shown that plant defence signalling from companion plants can be exploited to recruit natural enemies for conservation biological control of stemborer moth pests (Crambidae) (Khan et al. 2014; Pickett et al. 2014; Pickett and Khan 2016). Furthermore, some local farmers' maize genotypes have been identified to possess a rapid plant response to stemborer oviposition, compared to commercial hybrid varieties, resulting in enhanced recruitment of egg and larval parasitoids (Tamiru et al. 2011). Variability in the production of herbivore-induced signalling by maize genotypes can potentially interfere with plant resistance against herbivores and natural enemy recruitment (Gouinguené et al. 2001; Degen et al. 2004). The selection of genotypes that are capable of recruiting natural enemies requires an understanding of the chemical ecology of plant/herbivore/natural enemy interactions. To use a 'smart' plant, for example, that attracts natural enemies of the attacking herbivores, it is necessary to select a genotype appropriate for this, because not all genotypes will work efficiently for the attraction of predators and parasitoids (Gouinguené et al. 2001; Degen et al. 2004).

The egg parasitoid, Telenomus remus Nixon, 1937 (Hymenoptera: Platygastridae), is a beneficial natural enemy of Spodoptera spp. It is native to Asia (Wojcik et al. 1976) and was brought into Brazil in 1986 (Carneiro et al. 2010). Previous field and laboratory experiments reported a high potential of parasitism against several Spodoptera spp., with a preferred host being $S$. frugiperda (Figueiredo et al. 1999, 2002; Cave 2000; van Lenteren and Bueno 2003; Bueno et al. 2010; Pomari et al. 2013). T. remus uses different cues to locate its host, including Spodoptera spp. sex pheromone components (Nordlund et al. 1983; Gazit et al. 1996) and herbivore-induced plant volatiles (HIPVs) after association with $S$. frugiperda eggs (Peñaflor et al. 2011a). HIPVs might be beneficial to egg parasitoids, especially when eggs and larvae co-occur, because HIPVs are released in higher amounts compared to oviposition-induced plant volatiles (OIPVs) or volatiles directly from eggs (Hilker and McNeil 2008; Peñaflor et al. 2011b; Michereff et al. 2016). A previous study reported that $S$. frugiperda egg deposition on maize plants suppresses the emission of constitutive volatiles and HIPVs. The authors suggested that this effect could be a defence strategy to benefit the herbivore, since by decreasing plant volatile emissions, the egg parasitoid could not find its host (Peñaflor et al. 2011b). On the other hand, Bruce et al. (2010) proposed that the suppression of volatile emission by eggs laid on plants also might be important information for natural enemies to follow. Overlapping generations are observed in S. frugiperda (Figueiredo et al. 2006); therefore, parasitoids that parasitize eggs from $S$. frugiperda can follow HIPVs as a reliable cue to find egg hosts.

It is known that $T$. remus populations do not survive after a maximum of one generation in field conditions in Brazil. However, different studies have shown the potential of this parasitoid for $S$. frugiperda control through massrearing and inundative release (Joshi et al. 1982; Cave 2000; Pomari et al. 2013). Therefore, semiochemicals such as HIPVs, OIPVs, and insect pheromones could be used to attract and retain $T$. remus populations, enhancing its 
efficiency in crop areas (Cave 2000; Bueno et al. 2010; Pomari et al. 2013). Lewis and Nordlund (1984) suggested the use of parasitoids in inundative programmes to control S. frugiperda and the application of pheromones and kairomones to increase the attraction and retention of natural enemies. Moreover, evaluating the chemical profile of volatiles produced by different maize genotypes, and the influence of these blends on the attraction of T. remus, is essential information for pest control, in particular for biological control. Considering this information, the aims of this study were to evaluate (1) variation in the response of six different genotypes of maize to $S$. frugiperda herbivory damage, (2) whether T. remus could distinguish this variation, and (3) whether T. remus also respond by associative conditioning to HIPVs emitted by these genotypes.

\section{Materials and methods}

\section{Insects}

S. frugiperda and T. remus were maintained in separated environmental rooms at $25 \pm 2{ }^{\circ} \mathrm{C}, 65 \pm 10 \%$ relative humidity, and a $14 \mathrm{~L} / 10 \mathrm{D}$ photoperiod at Embrapa Genetic Resources and Biotechnology in Brasília, DF,

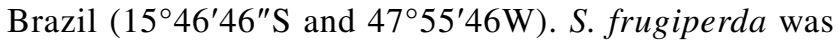
obtained from a laboratory colony maintained in plastic containers with an artificial diet based on beans, Phaseolus vulgaris L. (Fabaceae) (Schmidt et al. 2001). Each plant received five second instar larvae, and prior to the experiments, larvae were starved for $24 \mathrm{~h}$. The egg parasitoid $T$. remus was obtained from a laboratory colony raised on S. frugiperda eggs. At emergence, the adults were maintained in acrylic cages $\left(75 \mathrm{~cm}^{2}\right.$ angled neck tissue culture flasks; ICN Biomedicals, Irvine, CA, USA) and fed with a drop of honey. As showed by a previous study, experienced females responded better to HIPVs than naïve females (Peñaflor et al. 2011a); therefore, two-day-old females with oviposition experience were used in the experiments. For oviposition experience and associative conditioning with HIPVs and eggs, females were kept in acrylic cages after hatching for $24 \mathrm{~h}$ for mating; then, ten mated females were released in a cylindrical glass chamber with 100 host eggs glued on paper cards and placed on leaves of plants infested with $S$. frugiperda larvae (releasing HIPVs) for $1 \mathrm{~h}$. To obtain plants releasing HIPVs, 15-day-old maize received five second instar larvae for $24 \mathrm{~h}$. Only female T. remus that were parasitizing the eggs were used in the following day in olfactometer bioassays (Peñaflor et al. 2011a). This procedure was done for each maize genotype.

\section{Plants}

Maize seeds were obtained from the germplasm bank of Embrapa Maize and Sorghum in Sete Lagoas, MG, Brazil $\left(19^{\circ} 27^{\prime} 57^{\prime \prime} \mathrm{S}\right.$ and $\left.44^{\circ} 14^{\prime} 48^{\prime \prime} \mathrm{W}\right)$, and were germinated on damp paper. After 4 days, they were transplanted to pots with a mixture of soil and organic substrate (in a proportion of $1: 1 \mathrm{w} / \mathrm{w})$ and kept in a greenhouse (14L/10D photoperiod). The plants used in the experiments had three fully expanded leaves. Two groups of genotypes were assessed with differing levels of resistance to $S$. frugiperda: more resistant (the landrace Zapalote Chico (ZC), Mirt2A, and Sintético Spodoptera (SS)), less resistant (L3), and also commercial genotypes (BRS 4103 and BRS 1040). The mechanisms of resistance for Zapalote Chico and Mirt2A are antibiosis and/ or antixenosis and antixenosis for Sintético Spodoptera (Silveira et al. 1997; Viana and Potenza 2000; Costa et al. 2006).

\section{Y-tube olfactometer bioassays with Telenomus remus}

To evaluate whether volatiles emitted from undamaged and $S$. frugiperda-damaged plants affected $T$. remus searching behaviour, Y-tube olfactometer bioassays were conducted. The olfactometer consisted of square acrylic blocks $(19 \times 19 \mathrm{~cm})$ with a $1 \mathrm{~cm}$ Y-shaped cavity sandwiched between two glass plates (Moraes et al. 2008). The leg of the cavity was $8 \mathrm{~cm}$ long, and each arm was $7 \mathrm{~cm}$ long. Charcoal-filtered and humidified air was pushed through the system at a rate of $0.61 \mathrm{~min}^{-1}$ and pulled out at $0.21 \mathrm{~min}^{-1}$. A single T. remus female was introduced at the base of the Y-tube and observed for $600 \mathrm{~s}$. The first choice (defined as the arm of the olfactometer that the wasp entered at first and remained in for at least $30 \mathrm{~s}$ ) and the residence time (the total time that the parasitoid remained in each arm) were assessed during the bioassays. After every five repetitions, the plants were replaced, and the positions of the arms of the olfactometer were changed to avoid bias in the parasitoid responses. Each female was used only once, and 40 repetitions were conducted for the following treatment combination: (1) volatiles from $S$. frugiperda-damaged maize plants vs. volatiles from undamaged maize plants; (2) volatiles from S. frugiperda-damaged maize plants vs. air, and (3) volatiles from undamaged maize plants versus air. To avoid possible chemical signalling between plants, $S$. frugiperdadamaged and undamaged plants were kept in different rooms under the same temperature, humidity, and lighting conditions $\left(26 \pm 1^{\circ} \mathrm{C}, 65 \pm 10 \%\right.$ r.h., and 14L/10D photoperiod). The plants were infested with $S$. frugiperda larvae during the morning or afternoon, and these plants were used with $23 \mathrm{~h}$ after S. frugiperda treatment. The larvae remained on the plants during all experiment. All bioassays were conducted from 10:00 h to 18:00 $\mathrm{h}$. 


\section{Volatile collection}

Undamaged and $S$. frugiperda-damaged plants were placed individually in cylindrical glass chambers (internal volume 10 1). Volatiles were collected from the same individual plant at $0-3 \mathrm{~h}, 3-6 \mathrm{~h}, 6-12 \mathrm{~h}$, and $12-24 \mathrm{~h}$ after infestations were initiated ( $N=6$ replicates for each time and genotype). Larvae remained on the plants during all experiments. To minimize contamination by volatiles from the soil, the pots were wrapped with aluminium foil. A glass tube containing the adsorbent Porapak Q (100 mg, 80-100 mesh, SigmaAldrich) was connected via a PTFE tubing to a vacuum pump at $0.61 \mathrm{~min}^{-1}$, while activated charcoal-filtered air at $1.01 \mathrm{~min}^{-1}$ entered the chamber, creating a positive push-pull system (Moraes et al. 2008). The trapped volatiles were eluted from the adsorbent using $500 \mu \mathrm{l}$ of $\mathrm{n}$-hexane and concentrated to $50 \mu \mathrm{l}$ under a $\mathrm{N}_{2}$ flow. Samples were stored at $-20{ }^{\circ} \mathrm{C}$ until analysis by gas chromatography (GC) and $\mathrm{GC}$-coupled mass spectrometry (GC-MS).

\section{Chemical analysis}

Collected volatiles were analysed by gas chromatography (Agilent 7890A) using a $30 \mathrm{~m} \times 0.25 \mathrm{~mm}$ ID and $0.25 \mu \mathrm{m}$ film thickness column (DB-5MS, J\&W Scientific, Folsom, CA, USA). The oven temperature was programmed as follows: $50{ }^{\circ} \mathrm{C}$ for $2 \mathrm{~min}$, increase at $5{ }^{\circ} \mathrm{C} \mathrm{min}-1$ to $180{ }^{\circ} \mathrm{C}$, then $10^{\circ} \mathrm{C} \mathrm{min}^{-1}$ to $250^{\circ} \mathrm{C}$, and held for $20 \mathrm{~min}$. The carrier gas was helium. The column effluent was analysed with a flame ionization detector (FID) at $270{ }^{\circ} \mathrm{C}$. One microlitre of 16-hexadecanolide was added as an internal standard (IS) with a final concentration of $9.8 \mu \mathrm{g} \mathrm{ml}^{-1}$. One microlitre of each sample was injected using splitless mode. The amounts of volatile chemicals released by maize at $0-3 \mathrm{~h}, 3-6 \mathrm{~h}$, 6-12 $\mathrm{h}$, and 12-24 $\mathrm{h}$ were calculated in relation to the area of the internal standard. Data were collected with EZChrom Elite software (Agilent, California, USA) and were handled using Excel (Microsoft Corporation, 2007). Selected volatile samples were analysed using an Agilent 5975-MSD instrument equipped with a quadrupole analyser, a nonpolar DB$5 \mathrm{MS}$ column $(30 \mathrm{~m} \times 0.25 \mathrm{~mm}$ ID and $0.25 \mu \mathrm{m}$ film thickness; J\&W Scientific, Folsom, CA, USA), and a splitless injector with helium as the carrier gas. Ionization was by electron impact ( $70 \mathrm{eV}$ and source temperature at $230{ }^{\circ} \mathrm{C}$ ). The oven temperature was maintained at $50^{\circ} \mathrm{C}$ for $2 \mathrm{~min}$ and programmed to increase at $5{ }^{\circ} \mathrm{C} \mathrm{min}^{-1}$ to $180^{\circ} \mathrm{C}$, then $10^{\circ} \mathrm{C}$ $\mathrm{min}^{-1}$ to $250{ }^{\circ} \mathrm{C}$, and held for $20 \mathrm{~min}$. The absolute configuration of linalool released by different maize genotypes was determined by enantioselective gas chromatography using a chiral GC column $(30 \mathrm{~mm} \times 0.25 \mathrm{~mm}$, ID, $0.25-\mu \mathrm{m}$, $\beta$-DEX 325 matrix nonbonded with $25 \% 2$,3-di- $O$-acetyl6 - $O$-TBDMS- $\beta$-cyclodextrin in SPB- 20 poly ( $20 \%$ phenyl/80\% dimethylsiloxane phase), Supelco, USA). The oven temperature was programmed as follows: $50{ }^{\circ} \mathrm{C}$ for $2 \mathrm{~min}$, increase at $2{ }^{\circ} \mathrm{C} \mathrm{min}-1$ to $210{ }^{\circ} \mathrm{C}$, and then held for $10 \mathrm{~min}$. Injections were made in splitless mode with helium as the carrier gas $\left(1.5 \mathrm{ml} \mathrm{min}^{-1}\right)$, injector temperature at $250{ }^{\circ} \mathrm{C}$, and detector temperature at $270{ }^{\circ} \mathrm{C}$. Data were collected and analysed with GC-MS ChemStation 2.1 software (Agilent, California, USA). The compounds were tentatively identified by comparing the fragmentation pattern from the mass spectra with library databases (NIST, 2008) or published spectra and with retention indices calculated using a DB$5 \mathrm{MS}$. Tentative compound identification was confirmed by GC peak enhancement using authentic standards obtained either from commercial suppliers or by chemical synthesis.

\section{Chemicals}

$n$-Hexane (95\%, suitable for pesticide residue analysis), Porapak Q, 6-methyl-5-hepten-2-one (98\%), indole (99\%), $\alpha$-camphene (95\%), $(E)$-caryophyllene (98\%), benzothiazole $(96 \%)$, myrcene $(95 \%)$, geranylacetone $(97 \%)$, ocimene (mixture of isomers, $>90 \%$ ), $\alpha$-humulene (96\%), and geranyl acetate $(97 \%)$ were purchased from Sigma-Aldrich (Steinheim, Germany). (E)-2-Hexenal (95\%) and (Z)-3-hexen-1-ol (98\%) were purchased from Sigma-Aldrich (Gillingham, UK). (E)- $\beta$-Farnesene (98\%) was provided by Shin-Etsu (Japan). (Z)-3-Hexenyl acetate (98\%) was purchased from Alfa Aesar (Heysham, UK). (E)-2-Hexenyl acetate (97\%) and linalool were purchased from TCI America (Portland, USA). (E)-4,8-Dimethyl-1,3,7-nonatriene (DMNT) (95\%) and $(E, E)-4,8,12$-trimethyl-1-,3,7,11-tridecatetraene (TMTT) (97\%) were synthesized from geraniol and $(E, E)$ farnesol, respectively (Leopold 1990).

\section{Statistical analysis}

Data from bioassays were analysed to evaluate the influence of the individuals using generalized linear model (GLM) for repeated measures with binomial distribution (S1). Then, the first-choice response of the egg parasitoid was analysed using logistic regressions to estimate the probability of each choice (Magalhães et al. 2016; Michereff et al. 2016). The model fitted the side (left or right) on which the test odour was presented. The hypothesis of no preference (i.e. the proportion of choosing each odour $=0.5$ ) was tested by the Chi-square Wald test. The data for the residence time were analysed by the paired $t$ test for dependent samples. If wasps did not move after $3 \mathrm{~min}$, they were considered as nonresponding and were not included in the statistical analysis.

To evaluate the effect of the individual on the total amount of volatiles (S2) and class of compounds in each treatment (S3), the data were submitted to a repeated measurement with linear mixed model (LMM) fitted by maximum likelihood. If the individual did not show a significant effect, 
the classical statistical GLM was applied using Gamma distribution and inverse link function. If GLM showed significant difference, the data were submitted to contrast analysis, and for LMM were applied a simultaneous test for general linear hypotheses with multiple comparisons of means: Dunnett contrasts. The change in the chemical profile of undamaged and $S$. frugiperda-damaged maize plants over time was assessed using principal response curves (PRC) analysis (Michereff et al. 2011). This multivariate technique allows the assessment of repeated measurements over time, focusing on the proportion of variance explained by the treatments and the time compared to the control (undamaged plants). In each set of analyses, the significance was determined by a Monte Carlo permutation test. All analyses were performed using the statistical programme R 3.3.2 (R Development Core Team 2009).



C

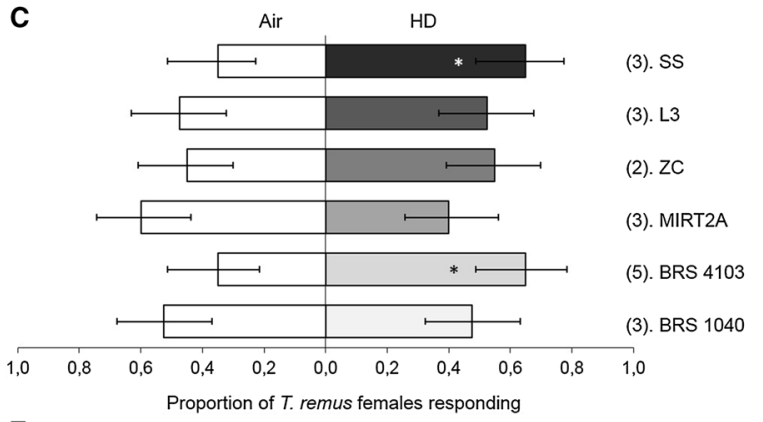

E

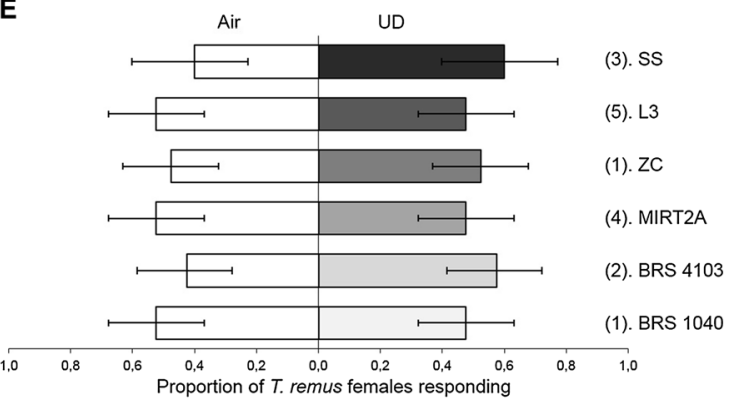

\section{Results}

\section{Telenomus remus foraging behaviour to maize volatiles}

In first-choice tests, female egg parasitoids $T$. remus responded preferentially to the volatiles from $S$. frugiperda-damaged maize SS, when compared to volatiles from undamaged SS (Fig. 1a, Table 1). T. remus showed no discrimination for any of the other tested genotypes (Fig. 1a, Table 1). For residence time, a similar response was obtained, female $T$. remus spent more time in the arm of the olfactometer containing the volatiles from $S$. frugiperda-damaged SS and BRS 4103 compared to the volatiles from the undamaged plants, while none of the other

B

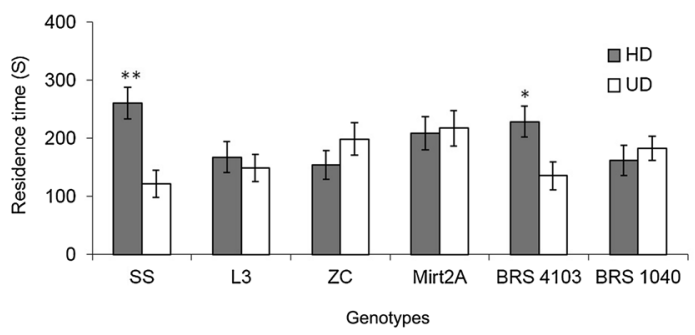

D

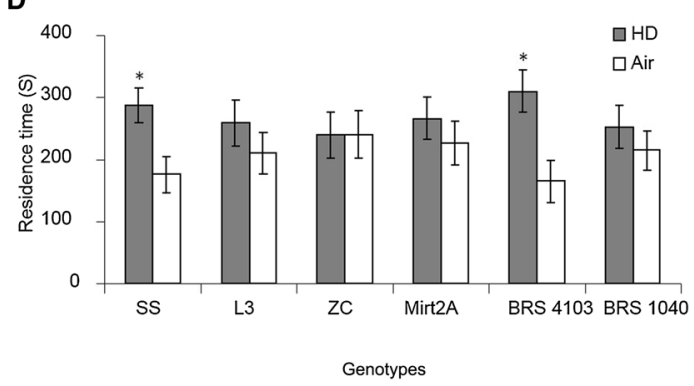

$\mathbf{F}$

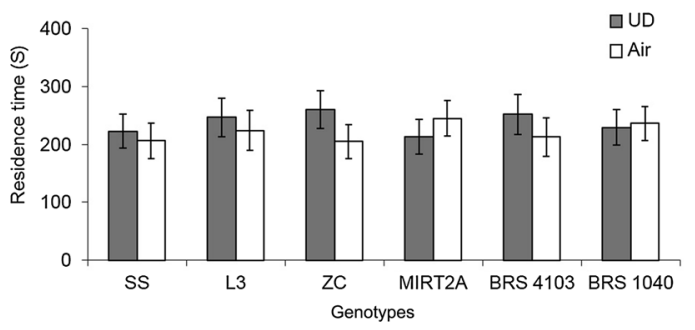

Fig. 1 First choice $(\mathbf{a}, \mathbf{c}, \mathbf{e})$ and residence time $(\mathbf{b}, \mathbf{d}, \mathbf{f})$ of the egg parasitoid Telenomus remus in a Y-tube olfactometer to volatiles of different maize genotypes. a, b Undamaged maize volatiles (UD) versus herbivore-induced maize volatiles (HD); c, $\mathbf{d}$ air control versus herbivore-induced maize volatiles (HD); e, f air control versus undamaged maize volatiles (UD). Induction time for herbivore-dam- aged treatments: $24 \mathrm{~h}$. Asterisks in a, c, e indicate significant differences between treatments using the Wald test with $\chi^{2}$ distribution at $0.05 \%$ significance level and in $\mathbf{b}, \mathbf{d}, \mathbf{f}$ indicate significant differences between treatments using the paired $t$ test at $0.05 \%$ significance level. Numbers in parentheses indicate the wasps that did not respond to any treatments 
Table 1 Statistical analysis of the first-choice and residence time data for female Telenomus remus in Y-tube olfactometer bioassays with volatiles from maize plants submitted to different treatments (12-24 h
Spodoptera frugiperda herbivory damage, undamaged maize plants, and air control)

\begin{tabular}{|c|c|c|}
\hline & \multicolumn{2}{|l|}{ T. remus response } \\
\hline & First choice & Residence time \\
\hline \multicolumn{3}{|c|}{ Volatiles from S. frugiperda-damaged maize plant compared with volatiles from undamaged plants of the same genotype } \\
\hline Sintético Spodoptera & $\chi^{2}=6.031, P=0.014^{*}$ & $t=-3.1, P=0.002^{*}$ \\
\hline L3 & $\chi^{2}=0.398, P=0.0527$ & $t=0.425, P=0.673$ \\
\hline Zapalote Chico & $\chi^{2}=0.893, P=0.344$ & $t=-0.961, P=0.342$ \\
\hline Mirt2A & $\chi^{2}=0.893, P=0.344$ & $t=-0.155, P=0.877$ \\
\hline BRS1040 & $\chi^{2}=3.37 \mathrm{e}^{-31}, P=1.000$ & $t=-0.501, P=0.619$ \\
\hline BRS 4103 & $\chi^{2}=0.158, P=0.208$ & $t=2.01, P=0.021^{*}$ \\
\hline \multicolumn{3}{|c|}{ Volatiles from S. frugiperda-damaged maize plant compared with air } \\
\hline Sintético Spodoptera & $\chi^{2}=4.687, P=0.030 *$ & $t=2.029, P=0.049^{*}$ \\
\hline L3 & $\chi^{2}=0.099, P=0.751$ & $t=0.718, P=0.477$ \\
\hline Zapalote Chico & $\chi^{2}=0.398, P=0.527$ & $t=-0.005, P=0.995$ \\
\hline Mirt2A & $\chi^{2}=1.579, P=0.208$ & $t=0.602, P=0.550$ \\
\hline BRS1040 & $\chi^{2}=0.099, P=0.751$ & $t=0.593, P=0.556$ \\
\hline BRS 4103 & $\chi^{2}=6.031, P=0.014^{*}$ & $t=2.246, P=0.030^{*}$ \\
\hline \multicolumn{3}{|c|}{ Volatiles from S. frugiperda undamaged maize plant compared with air } \\
\hline Sintético Spodoptera & $\chi^{2}=1.531, P=0.215$ & $t=0.289, P=0.773$ \\
\hline L3 & $\chi^{2}=0.999, P=0.317$ & $t=0.346, P=0.730$ \\
\hline Zapalote Chico & $\chi^{2}=0.999, P=0.317$ & $t=0.940, P=0.352$ \\
\hline Mirt2A & $\chi^{2}=0.999, P=0.317$ & $t=-0.530, P=0.598$ \\
\hline BRS1040 & $\chi^{2}=0.893, P=0.344$ & $t=-0.109, P=0.913$ \\
\hline BRS 4103 & $\chi^{2}=0.999, P=0.317$ & $t=0.607, P=0.547$ \\
\hline
\end{tabular}

$* P<0.05 ; * * P<0.01 ; * * * P<0.001$

genotypes elicited any differential behaviour (Fig. 1b, Table 1). When $S$. frugiperda-damaged maize volatiles were tested against control air, $T$. remus responded preferentially and spent more time in the olfactometer arms with damaged plant volatiles emitted by SS and BRS 4103, but showed no preference for the other genotypes (Fig. 1c, d, Table 1). When the volatiles emitted from each undamaged genotype were compared to air, the egg parasitoid did not respond significantly to any treatment (Fig. 1e, Table 1) and similar results were obtained when the residence time was analysed (Fig. 1f, Table 1).

\section{Volatile analysis}

Chemical analysis of volatile samples collected from the six maize genotypes by air entrainment revealed that they produced similar blends of 21 major compounds (listed in Table 2), but with some notable differences. Volatiles obtained from ZC did not show the presence of $(E)$-ocimene, methyl benzoate, cyclosativene, $\delta$-cadinene, and $\alpha$-bergamotene (Table 2). (E)-4,8-Dimethyl-1,3,7-nonatriene (DMNT) was induced in five genotypes, except for Mirt2A (Table 2). Linalool was produced by undamaged and herbivore-damaged plants in all genotypes and was determined to be a racemic (equal) mixture of $(R)$ and $(S)$ isomers (S4 Fig). In addition to major compounds, other minor components were identified, including limonene, $(Z)$-ocimene, $(E)$-nerolidol, and unidentified sesquiterpenes. These compounds were not quantified due to the very low amount produced. Cyclosativene, $\alpha$-bergamotene, and $\delta$-cadinene were tentatively identified by comparison with mass spectra and retention indices, since no authentic standards were available.

Considering the 21 major compounds, the linear mixed model (LMM) did not show an influence of individual compounds to any of the genotypes, except for BRS1040 (S2). Therefore, GLM analysis was used to analyse the difference in total amount of volatiles between treatments throughout the sampling times for SS $(t=2.362, P=0.040)$ and $\mathrm{ZC}$ ( $t=8.852, P<0.01$ ) (Fig. 2). No difference was observed for the interaction of treatment and time for L3 $(t=1.668$, $P=0.148)$, Mirt2A $(t=0.787, P=0.603)$, and BRS 4103 $(t=1.109, P=0.381)$. However, there was difference between undamaged and $S$. frugiperda-damaged plants for Mirt2A $(t=-3.011, P=0.016)$ at $12-24 \mathrm{~h}$ and for BRS 4103 at 6-12 h $(t=-2.360, P=0.045)$ (Fig. 2). For BRS 1040, 


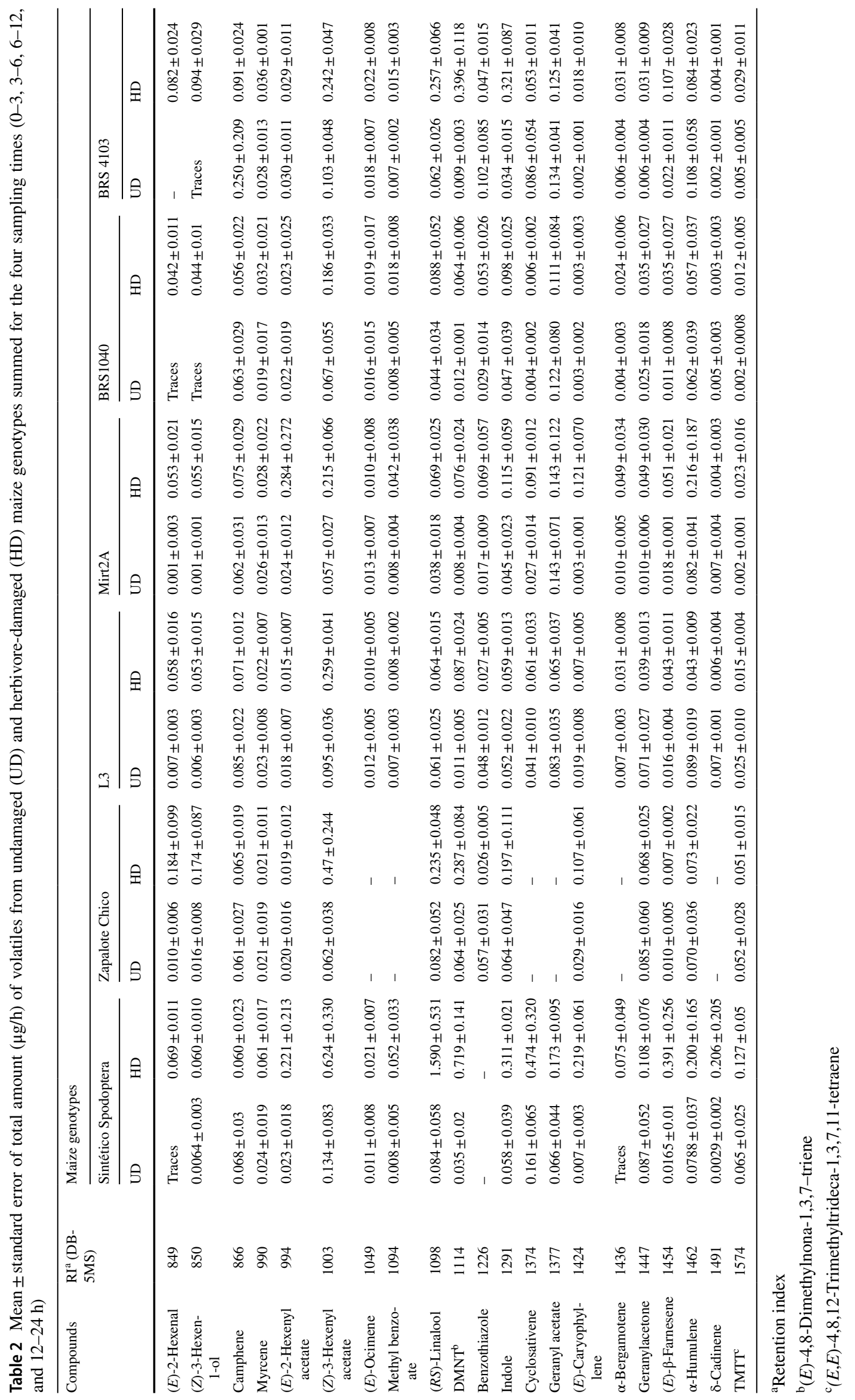


Fig. 2 Total amount of volatiles $(\mu \mathrm{g} / \mathrm{h})$ from undamaged (UD) and herbivore-induced (HD) plants of different maize genotypes. SS Sintético Spodoptera. ZC Zapalote Chico. Asterisks indicate significant differences (MANOVA for repeated measures, $P<0.05$ ) between treatments
A

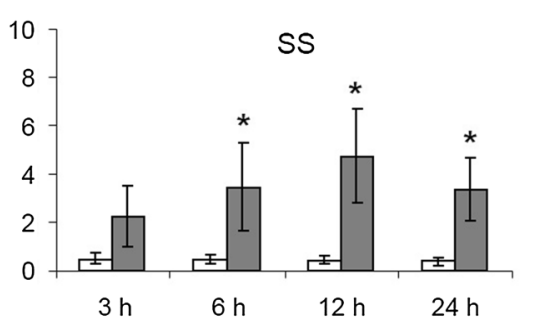

C

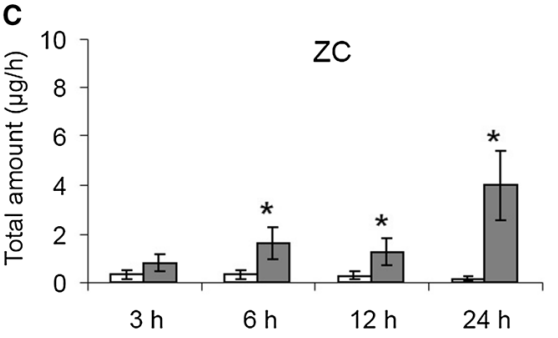

E

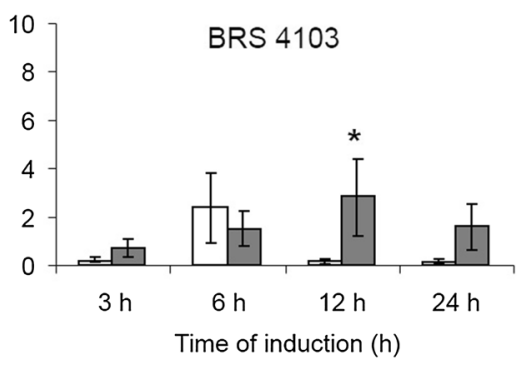

B

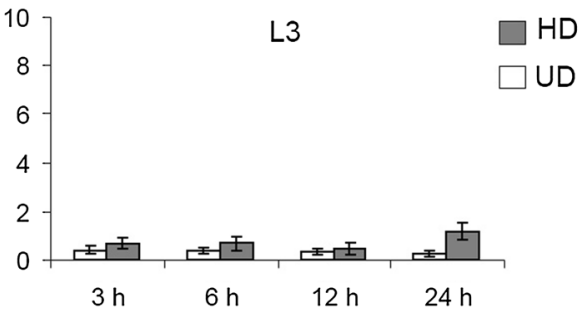

D

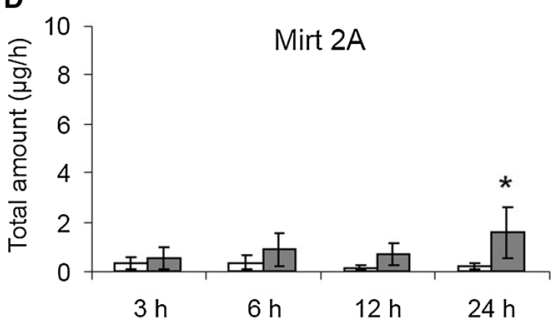

$\mathbf{F}$

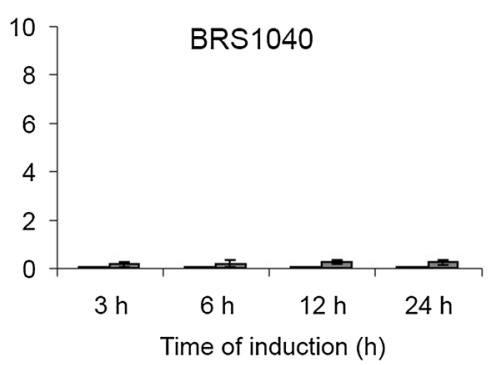

LMM showed that the total amount of volatiles differed between treatments ( $t=2.545, P=0.016)$, but there was no difference for the interaction of treatment and time (S2). Considering the genotypes SS, ZC, Mirt2A, and BRS4103, most HIPVs emissions occurred between 3-6, 6-12, and 12-24 h (Fig. 2). No significant variation in constitutive volatiles production was observed (Fig. 2).

Principal response curves (PRC) analysis evaluated whether the volatiles emitted along the time by herbivoredamaged plants were different from that of undamaged plants (Fig. 3). The main class of compounds responsible for differences between the treatments was identified using the weight value (left $Y$-axis, Fig. 3), in which values higher than $10.5 \mid$ represent an actual contribution of the compound to the accomplishment of the PRC. The emission of monoterpenes, homoterpenes, indole, and sesquiterpenes was different between undamaged and S. frugiperdadamaged plants for SS, BRS4103, and Mirt2A (Fig. 3, S3 and S5 Fig, Table 3). The green leaf volatiles (GLVs) were different between $S$. frugiperda-damaged and undamaged plants for all genotypes (Fig. 3, S3 and S5 Fig, Table 3). The first canonical axis of the PRC explained a significant part of the variance, described by the treatments higher than 96\% for SS, ZC, L3, BRS1040, and higher than 58\% for BRS 4103 (S6 Table). PRC analysis comparing the volatiles emitted by $S$. frugiperda-damaged and undamaged plants for SS revealed a significant difference between both treatments. PRC analysis showed that $3 \%$ of the total variance was explained by time and $23 \%$ by treatment. A significant part of variance, $94 \%$, was captured by the first axis of the PRC, indicating that these curves are representative of the data (S6 Table). The PRC plot for SS also showed that the major difference occurred at 3-6 $\mathrm{h}(P=0.039)$ and 6-12 $\mathrm{h}$ ( $P=0.018)$ (Fig. 3).

The highest compound weighting for SS was calculated for monoterpenes (MONO) (1.68) and homoterpenes (HOMO) (1.19). These two classes of compounds showed stronger increases, over time in SS, when the plants were subjected to S. frugiperda damage (Fig. 3). Analogous to SS, the PRC results for the other genotypes had their highest variance percentage explained by treatment, followed by time, and a significant part of the variability was captured by the PRC first canonical axis (S6 Table). At 6-12 h, for BRS1040, treatments were statistically different $(P=0.011)$, and the highest weight was for GLVs (0.742). For BRS4103, two compound classes presented the highest weights: monoterpenes (MONO) (0.937) and sesquiterpenes (SESQUI) (0.937); however, a significant difference between the sampling times was recorded only at 6-12 h $(P=0.040)$ and 12-24 h ( $P=0.017)$ (Fig. 3). For ZC, Mirt2A, and L3, 

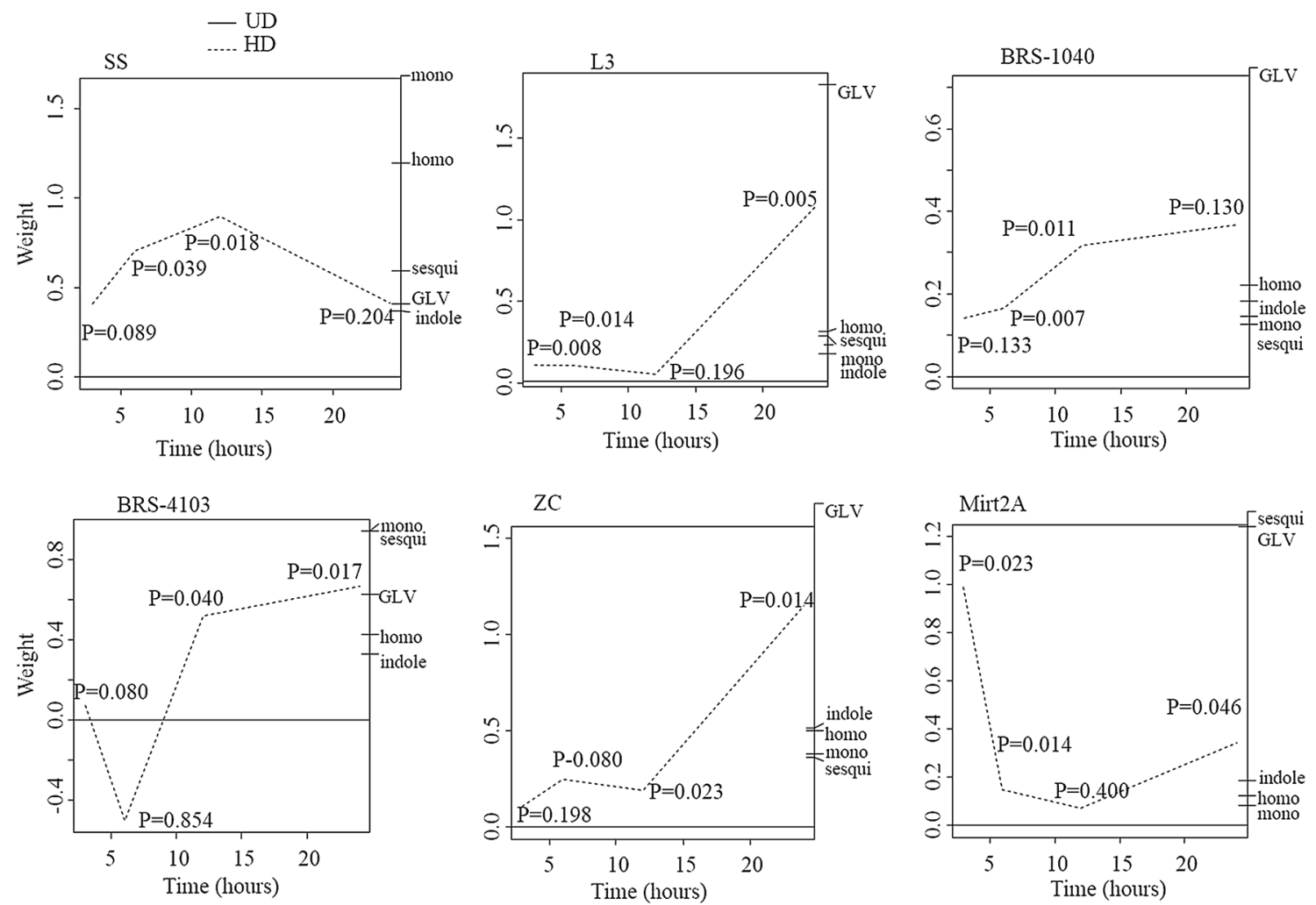

Fig. 3 PRC diagram and variables weights based on volatile blends released by different maize genotypes on four sampling times. The lines represent the response pattern of maize to different treatments in time. The $P$ values indicate significance of the PRC diagram over all

the sampling times were statistically different, and the compounds presented higher weight values, but a different class of compounds was induced. For the ZC and L3, the GLVs had the highest compound weight (1.678 and 1.824, respectively), while for Mirt2A, the highest were the GLVs (1.239) and the sesquiterpenes (SESQUI) (1.303) (Fig. 3). All these weights were at the same side of the PRC curve, indicating that these compounds are related to higher production of volatiles in herbivore-damaged plants.

\section{Discussion}

Plant volatiles are an important cue for host-searching insect parasitoids. In this study, the egg parasitoid $T$. remus changed its searching behaviour when stimulated with HIPVs emitted by $S$. frugiperda-damaged maize genotypes after associative conditioning. Oviposition damage can change the volatiles emitted by plants, releasing OIPVs and attracting egg parasitoids (Chiappini et al. 2012; Hilker and Fatouros 2015), but for some tritrophic systems, egg parasitoids are attracted only to HIPVs combined with OIPVs (Colazza et al. 2004; Michereff et al. 2011) or exclusively to HIPVs (Moraes et al. sampling times based on Monte Carlo permutation test. The higher (absolute values) the variable weight, the more closely the compound response pattern follows the deviation pattern (from the control, control $=0$ line) indicated on the PRC plots

2008). Recently, it was reported that the egg parasitoid $T$. podisi Ashmead, 1893 (Hymenoptera: Platygastridae), was attracted to volatiles from fresh eggs of its preferred host, Euschistus heros Fabricius, 1798 (Heteroptera: Pentatomidae), but was not attracted to egg masses laid on soybean plants (Michereff et al. 2016). The authors hypothesized that the volatiles from soybean might have masked the volatiles from the eggs. Eggs are small and release very tiny amounts of volatiles and therefore are probably detectable only at short range (Vet and Dicke 1992; Wajnberg 2006; Wäschke et al. 2013). The ability to learn host cues might be a strategy to cope with high environmental variability for both specialist and generalist parasitoids (Steidle and van Loon 2003). $T$. remus, a specialist parasitoid, after associative conditioning, can use the volatiles that plants emit in response to herbivory in order to locate the host plant of their own hosts, and this behaviour could help to improve maize fitness by reducing the density of herbivores on the plant (Peñaflor et al. 2011a).

From the six genotypes evaluated, T. remus was able to recognize the HIPVs of SS and BRS4103, after associative conditioning. PRC analysis showed that these two genotypes had a relatively higher production of monoterpenes, homoterpenes, and sesquiterpenes, which are major 
Table 3 Statistical analysis of the difference in the volatiles released by Spodoptera frugiperda-damaged maize plants compared to volatiles from undamaged plants of the same genotype. The influence of compounds in each treatment was analysed using GLM with Gamma distribution and inverse link function

\begin{tabular}{|c|c|c|c|c|}
\hline \multirow{2}{*}{$\begin{array}{l}\text { Class of compounds/ } \\
\text { genotypes }\end{array}$} & \multicolumn{4}{|l|}{ Time collections (h) } \\
\hline & $0-3$ & $3-6$ & $6-12$ & $12-24$ \\
\hline \multicolumn{5}{|l|}{ Monoterpenes } \\
\hline SS & $t=-1.853, P=0.093$ & $t=-2.385, P=0.038^{*}$ & $t=-2.276, P=0.046^{*}$ & $t=-1.445, P=0.179$ \\
\hline L3 & $t=-1.470, P=0.172$ & $t=-1.045, P=0.320$ & $t=-0.765, P=0.473$ & $t=-1.757, P=0.109$ \\
\hline $\mathrm{ZC}$ & $t=-0.768, P=0.460$ & $t=-2.116, P=0.060$ & $t=-1.976, P=0.076$ & $t=3.416, P=0.009^{*}$ \\
\hline MIRT2A & $t=-1.184, P=0.263$ & $t=-0.882, P=0.403$ & $t=-0.865, P=0.436$ & $t=-2.012, P=0.061$ \\
\hline \multicolumn{5}{|l|}{ Homoterpenes } \\
\hline L3 & $t=-1.587, P=0.143$ & $t=-1.780, P=0.105$ & $t=-1.578, P=0.166$ & $t=-1.738, P=0.113$ \\
\hline $\mathrm{ZC}$ & $t=-0.760, P=0.465$ & $t=-1.600, P=0.140$ & $t=-1.944, P=0.080$ & $t=-2.594, P=0.031^{*}$ \\
\hline MIRT2A & $t=-1.484, P=0.169$ & $t=-1.961, P=0.073$ & $t=-1.675, P=0.169$ & $t=-1.876, P=0.064$ \\
\hline \multicolumn{5}{|l|}{ Sesquiterpenes } \\
\hline $\mathrm{ZC}$ & $t=0.056, P=0.956$ & $t=-1.396, P=0.192$ & $t=-0.034, P=0.087$ & $t=-2.321, P=0.042 *$ \\
\hline MIRT2A & $t=-1.401, P=0.191$ & $t=-1.306, P=0.227$ & $t=-0.955, P=0.393$ & $t=-1.756, P=0.083$ \\
\hline BRS4103 & $t=-0.230, P=0.824$ & $t=1.237, P=0.251$ & $t=-1.875, P=0.097$ & $t=-1.469, P=0.180$ \\
\hline BRS1040 & $t=-0.391, P=0.705$ & $t=0.545, P=0.600$ & $t=-1.829, P=0.104$ & $t=-1.438, P=0.188$ \\
\hline \multicolumn{5}{|l|}{$G L V s$} \\
\hline SS & $t=-1.795, P=0.103$ & $t=-1.783, P=0.104$ & $t=-2.315, P=0.046^{*}$ & $t=-1.339, P=0.074$ \\
\hline L3 & $t=-1.065, P=0.237$ & $t=-1.599, P=0.141$ & $t=1.567, P=0.125$ & $t=-2.681, P=0.036^{*}$ \\
\hline $\mathrm{ZC}$ & $t=-2.215, P=0.051$ & $t=-1.897, P=0.059$ & $t=-2.105, P=0.061$ & $t=-2.362, P=0.045^{*}$ \\
\hline MIRT2A & $t=-1.440, P=0.180$ & $t=-1.939, P=0.088$ & $t=-1.537, P=0.199$ & $t=-2.753, P=0.024 *$ \\
\hline BRS4103 & $t=-2.029, P=0.077$ & $t=0.070, P=0.946$ & $t=-2.794, P=0.023^{*}$ & $t=-2.188, P=0.060$ \\
\hline BRS1040 & $t=-1.836, P=0.103$ & $t=-2.875, P=0.020^{*}$ & $t=4.106, P=0.003^{* *}$ & $t=-2.578, P=0.032 *$ \\
\hline \multicolumn{5}{|l|}{ Indole } \\
\hline SS & $t=-1.400, P=0.192$ & $t=-1.943, P=0.080$ & $t=-2.416, P=0.042^{*}$ & $t=-2.153, P=0.037 *$ \\
\hline L3 & $t=-1.299, P=0.223$ & $t=-1.480, P=0.170$ & $t=-0.983, P=0.363$ & $t=-1.335, P=0.211$ \\
\hline $\mathrm{ZC}$ & $t=-0.804, P=0.440$ & $t=-1.809, P=0.106$ & $t=-1.710, P=0.118$ & $t=-2.938, P=0.018^{*}$ \\
\hline MIRT2A & $t=-1.287, P=0.227$ & $t=-1.083, P=0.310$ & $t=-0.990, P=0.378$ & $t=-1.628, P=0.142$ \\
\hline BRS1040 & $t=-1.152, P=0.283$ & $t=-1.241, P=0.250$ & $t=-2.032, P=0.076$ & $t=-1.584, P=0.152$ \\
\hline
\end{tabular}

$* \mathrm{P}<0.05 ; * * \mathrm{P}<0.01$

and ubiquitous parasitoid foraging cues compared to other classes of compounds (Büchel et al. 2011; Michereff et al. 2011; Tamiru et al. 2011). Higher production of HIPVs from different varieties and landraces of maize was observed when treated with regurgitate of S. littoralis Boisduval, 1833 (Lepidoptera: Noctuidae), 10-13 h after the beginning of treatment (Gouinguené et al. 2001). A similar time to detect HIPVs was found in our study, confirming that maize plants take time to produce HIPVs following damage by Spodoptera spp. The chemical composition of the blends emitted by the six genotypes studied here, and other maize varieties and teosintes, Zea spp. studied elsewhere (Gouinguené et al. 2001), was broadly similar, but some significant differences were observed. Qualitative differences were noticed; for example, phenylethyl acetate, $\beta$-bisabolene, $(E, E)$ - $\alpha$-farnesene, and hexyl acetate were not detected in the genotypes studied here, and there were some compounds identified in this study that were not cited previously in the other maize varieties and teosintes. The differences in the chemical profile can be related to differences due to the genetic characteristics of each genotype, but also can be due to the specific response of maize plants to the herbivores used. Further studies need to be conducted to clarify this and to evaluate the response of natural enemies to HIPVs from different maize genotypes damaged by different herbivores. Work is ongoing in our laboratory to elucidate the influence of specific volatiles on $T$. remus and $S$. frugiperda behaviour.

The difference in quantities of the compounds emitted by each genotype can explain the response of the egg parasitoid to SS and BRS4103, indicating that higher production of monoterpenes, homoterpenes, and sesquiterpenes and the lower increase of herbivore-induced GLVs relative to the terpenes might be important for egg parasitoid attraction. On the other hand, ZC genotype produced a blend of HIPVs 
composed of lower levels of monoterpenes, sesquiterpenes, and homoterpenes and higher levels of GLVs, which might have influenced the nonresponse of $T$. remus to the induced volatiles of this genotype. Wäschke et al. (2013) suggested that for certain compounds of a mixture, learning can be blocked by other components, which might have occurred in this work. HIPVs released by plants are complex blends, with the ratio between the components being the critical source of information for natural enemies to locate the plant with their host (D'Alessandro and Turlings 2005; D'Alessandro et al. 2006; Bruce et al. 2010; Bruce and Pickett 2011; Michereff et al. 2013; McCormick et al. 2014). We hypothesize that the terpenoids are the primary factor influencing the response of the egg parasitoid $T$. remus. GLVs are important compounds in plant-plant and plant-insect communication (Allmann and Baldwin 2010; Simpson et al. 2011; Vieira et al. 2014; von Mérey et al. 2011). Although GLVs were less induced in all genotypes than the monoterpenoids, these chemicals were produced in higher amounts in herbivore-damaged plants compared to undamaged plants, and they were released with a similar pattern across time. This is in contrast to indole, which displayed a different release pattern between genotypes across time. This compound does not appear to be involved in the foraging behaviour of parasitic wasps (D'Alessandro and Turlings 2005; D'Alessandro et al. 2006; Turlings and Erb 2018), but appears to play a key role in plant-plant communication (Erb et al. 2015).

Differences in parasitoid attraction to different maize genotypes have also been observed for larval parasitoids. The GLV (E)-2-hexenal was negatively correlated with Campoletis sonorensis (Cameron, 1886) (Hymenoptera: Ichneumonidae) parasitism, whereas methyl salicylate was positively correlated with Cotesia marginiventris (Cresson, 1865) (Hymenoptera: Braconidae) parasitism (Degen et al. 2012; de Lange et al. 2016). Therefore, the quality and the quantity of the volatiles emitted by plants can be used as information by egg parasitoids as a means by which to locate their hosts (Heil 2004; Hilker and Meiners 2006; Schröder and Hilker 2008; Michereff et al. 2013). It would be unadvisable to discard the influence of the minor components from maize volatile blend in T. remus attraction. Very often, relevant compounds to natural enemy attraction include minor components of the volatile profile, which might be the case here (Turlings et al. 1998; Mumm et al. 2003; Mumm and Hilker 2005; Michereff et al. 2016).

Spodoptera frugiperda-resistant maize genotypes are not related to higher attraction to $T$. remus, since the response of the egg parasitoid to ZC, Mirt2A, and L3 was different from that of SS and BRS4103. A different result was observed in a tritrophic system involving soybean, the stink bug E. heros, and $T$. podisi, where the latter was attracted to a resistant genotype, but not to a susceptible genotype. This was related to the production of higher amounts of volatiles by the resistant soybean genotype (Michereff et al. 2011). The same pattern was not observed for maize genotypes evaluated here, and there was no clear correlation between resistance in maize genotypes to $S$. frugiperda and volatile production, i.e. indirect defence. The resistance of genotypes, in general, is not related to the attraction of natural enemies or with the production of volatiles involved in indirect defence. The resistance of these plants is more related to antibiosis and nonpreference.

A genotype that is resistant to herbivores and at the same time attracts natural enemies would be the best choice to be used in the field, since it could then reduce the amount of insecticides needed in maize fields. However, there is little information regarding these characteristics for most of the genotypes currently in use. The results in our study highlight the need for including chemical ecology research in the selection of genotypes, so that the resulting selections possess $S$. frugiperda-resistant traits but also can recruit its natural enemies, for biological control using mass-rearing and inundative programmes. When used in combination with other control methods, e.g. cultural practices and crop rotation, the use (and costs) of insecticides could be reduced, and the ecological sustainability of agricultural systems would be enhanced. Furthermore, the results in our study provide the basis for testing the hypothesis that early onset of pest status in crop plants is accompanied by upregulation of genes responsible for the production and emission of volatile plant defence signals, which are released even before normal and recognizable symptomology. These results also provide the platform for utilizing molecular genetic approaches, in particular next-generation sequencing (NGS), for the identification of genetic targets that could be delivered in maize, through seed, via breeding and GM technologies, for improved biological control of S. frugiperda, along with other desirable traits.

\section{Authors' contribution}

MCBM, MAB, RL, PR, PV, PG, and MB made substantial contributions to the conception and design of the experiments. MCBM, MFFM, DMM, MJH, PHCS and JZ made substantial contributions to the design, analysis, and acquisition of data. All authors either participated in the drafting of the manuscript or revised it critically for content or undertook both activities.

Acknowledgements We thank Isabela Grisi, Sulian Gomes de Azevedo and Helio Moreira dos Santos for helping with laboratory rearing of the insects; Dr. Ivan Cruz for providing the egg parasitoid T. remus to establish our colony and the Post-Graduate Zoology Program of the University of Brasília (UnB) for use of their facility. 
Funding This work received financial support from the Coordination of Superior Level Staff Improving (CAPES) through a grant to MJH (88881.1317661/2014-01), the National Counsel of Technological and Scientific Development (CNPq), the Federal District Research Foundation (FAP-DF), and the Brazilian Corporation of Agricultural Research (EMBRAPA). The work at Rothamsted forms part of the Smart Crop Protection (SCP) strategic programme (BBS/OS/CP/000001) funded through Biotechnology and Biological Sciences Research Council's Industrial Strategy Challenge Fund.

\section{Compliance with ethical standards}

Conflict of interest The authors declare that they have no conflicts of interest.

Ethical approval This article does not contain any studies with human participants or animals performed by any of the authors.

\section{References}

Allmann S, Baldwin IT (2010) Insects betray themselves in nature to predators by rapid isomerization of green leaf volatiles. Science 329:1075-1078

Bernardi D, Salmeron E, Horikoshi RJ, Bernardi O, Dourado PM, Carvalho RA et al (2015) Cross-resistance between Cry1 proteins in fall armyworm (Spodoptera frugiperda) may affect the durability of current pyramided Bt maize hybrids in Brazil. PLoS ONE 10:e0140130. https://doi.org/10.1371/journal.pone.0140130

Bruce TJ, Pickett JA (2011) Perception of plant volatile blends by herbivorous insects-finding the right mix. Phytochemistry 72:1605-1611

Bruce TJA, Midega CAO, Birkett MA, Pickett JA, Khan ZR (2010) Is quality more important than quantity? Insect behavioural responses to changes in a volatile blend after stemborer oviposition on an African grass. Biol Lett 6:314-317

Büchel K, Malskies S, Mayer M, Fenning TM, Gershenzon J et al (2011) How plants give early herbivore alert: volatile terpenoids attract parasitoids to egg-infested elms. Basic Appl Ecol 12:403-412

Bueno RCOF, Carneiro TR, Bueno AF, Pratissoli D, Fernandes OA, Vieira SS (2010) Parasitism capacity of Telenomus remus Nixon (Hymenoptera: Scelionidae) on Spodoptera frugiperda (Smith) (Lepidoptera: Noctuidae) eggs. Braz Arch Biol Technol 53:133-139

Carneiro TR, Fernandes OA, Cruz I, Bueno RCO (2010) Functional response of Telenomus remus Nixon (Hymenoptera: Scelionidae) to Spodoptera frugiperda (JE Smith) (Lepidoptera: Noctuidae) eggs: effect of female age. Rev Bras Entomol 54:692-696

Cave RD (2000) Biology, ecology and use in pest management of Telenomus remus. Biocontrol News Inf (Dordr) 21:21-26

Chiappini E, Salerno G, Berzolla A, Iacavone A, Reguzzi MC, Conti E (2012) Role of volatile Semiochemicals in host location by the egg parasitoid Anagrus breviphragma. Entomol Exp Appl 144:311-316

Colazza S, McElfresh JS, Millar JG (2004) Identification of volatile synomones, induced by Nezara viridula feeding and oviposition on bean spp., that attract the egg parasitoid Trissolcus basalis. J Chem Ecol 30:945-964

CONAB (2017) Companhia Nacional de Abastecimento. Acompanhamento de safra brasileira: grãos, V4 safra 2016/2017. Décimo segundo levantamento, setembro 2017. Brasília-DF:
Conab. http://www.conab.gov.br/OlalaCMS/uploads/arqui vos/17_09_12_10_14_36_boletim_graos_setembro_2017.pdf

Costa LP, Sena MR, Guimarães PEO de, Viana PA, Pacheco CAP (2006) Avaliação de linhagens de milho para resistência à lagarta-do-cartucho, Spodoptera frugiperda (J. E. Smith). In: $26^{\circ}$ Congresso Nacional de Milho e Sorgo, Belo Horizonte, 2006. Available in: https://www.embrapa.br/busca-de-publi cacoes/-/publicacao/490124/avaliacao-de-linhagens-de-milho -para-resistencia-a-lagarta-do-cartucho-spodoptera-frugiperda -j-e-smith. Accessed 26 Feb 2018

Cruz I (1995) A lagarta-do-cartucho na cultura do milho. Circular Técnica/Embrapa Milho e Sorgo 21:45p

Cruz I, Figueiredo MLC, Silva RB (2010) Monitoramento de adultos de Spodoptera frugiperda (J. E. Smith) (Lepidoptera: Noctuidae) e Diatraea saccharalis (Fabricius) (Lepidoptera: Pyralidae) em algumas regiões produtoras de milho no Brasil. Documentos/Embrapa Milho e Sorgo 93:42

Cruz I, Figueiredo MLC, Silva RB, Silva IF, Paula CS, Foster JE (2012) Using sex pheromone traps in the decision-making process for pesticide application against fall armyworm (Spodoptera frugiperda [Smith] [Lepidoptera: Noctuidae]) larvae in maize. Int J Pest Manag 58:83-90

D'Alessandro M, Turlings TCJ (2005) In situ modification of herbivore-induced plant odors: A novel approach to study the attractiveness of volatile organic compounds to parasitic wasps. Chem Senses 30:739-753

D’Alessandro M, Held M, Triponez Y, Turlings TCJ (2006) The role of indole and other shikimic acid derived maize volatiles in the attraction of two parasitic wasps. J Chem Ecol 32:2733-2748

de Lange ES, Farnier K, Gaudillat B, Turlings TCJ (2016) Comparing the attraction of two parasitoids to herbivore-induced volatiles of maize and its wild ancestors, the teosintes. Chemoecology 26:33-44

Degen T, Dillmann C, Marion-Poll F, Turlings TCJ (2004) High genetic variability of herbivore-induced volatile emission within a broad range of maize inbred lines. Plant Physiol 135:19281938. https://doi.org/10.1104/pp.104.039891

Degen T, Bakalovic N, Bergvinson D, Turlings TCJ (2012) Differential performance and parasitism of caterpillars on maize inbred lines with distinctly different herbivore-induced volatile emissions. PLoS ONE 7:1-14

Erb M, Veyrat N, Robert CAM, Xu H, Frey M, Ton J, Turlings TCJ (2015) Indole is an essential herbivore-induced volatile priming signal in maize. Nat Commun 6:1-10. https://doi.org/10.1038/ ncomms 7273

Farias JR, Andow DA, Horikoshi RJ, Sorgatto RJ, Fresia P, Santos AC, Omoto C (2014) Field-evolved resistance to Cry1F maize by Spodoptera frugiperda (Lepidoptera: Noctuidae) in Brazil. Crop Prot 64:150-158

Figueiredo MLC, Cruz I, Della Lucia TMC (1999) Controle integrado de Spodoptera frugiperda (Smith \& Abbott) utilizandose o parasitoide Telenomus remus Nixon. Pesq Agropec Bras 34:1975-1982

Figueiredo MLC, Della Lucia TMC, Cruz I (2002) Effect of Telenomus remus Nixon (Hymenoptera: Scelionidae) on control of Spodoptera frugiperda (J. E. Smith) (Lepidoptera: Noctuidae) egg masses upon release in a maize field. Rev Bras Milho e Sorgo 1:12-19

Figueiredo MLC, Martins-Dias AMP, Cruz I (2006) Relação entre a lagarta do cartucho e seus agentes de controle biológico natural na produção do milho. Pesq Agrop Bras 41:1693-1698

Galvão JCC, Miranda GV, Trogello E, Fritsche-Neto R (2014) Sete décadas de evolução do sistema produtivo da cultura do milho. Rev Ceres 61:819-828 
Gazit Y, Lewis WJ, Tumlinson JH (1996) Arrestment of Telenomus remus by a kairomone associated with eggs of its host Spodoptera frugiperda. Biol Control 6:283-290

Gouinguené S, Degen T, Turlings TCJ (2001) Variability in herbivoreinduced odours emissions among maize cultivars and their wild ancestors (teosinte). Chemoecol 11:9-16

Heil M (2004) Induction of two indirect defences benefits lima bean (Phaseolus lunatus, Fabaceae) in nature. J Ecol 92:527-536

Hilker M, Fatouros NE (2015) Plant responses to insect egg deposition. Ann Rev Entomol 60:26.1-26.23

Hilker M, McNeil J (2008) Chemical and behavioural ecology in insect parasitoids: how to behave optimally in complex odorous environment. In: Wajnber E, Bernstein C, van Alphen J (eds) Behavioral ecology of insect parasitoids: from theoretical approaches to field applications, 1st edn. Blackwell Publishing, Oxford, pp 92-128

Hilker M, Meiners T (2006) Early herbivore alert: insect eggs induce plant defense. J Chem Ecol 32:1379-1397

Joshi BG, Sitaramaiah S, Ramaprasad G (1982) Field observations on impact of egg parasite Telenomus remus (Hym:Scelionidae) on tobacco caterpillar, Spodoptera litura (Lep.: Noctuidae) in tobacco nurseries in Andhra Pradesh, India. Entomophaga 27:331-334

Khan ZR, Midega CAO, Pittchar JO, Murage AW, Birkett MA, Bruce TJA, Pickett JA (2014) Achieving food security for one million sub-Saharan African poor through push-pull innovation by 2020 . Philos Trans R Soc B 369:1-10

Leopold EJ (1990) Selective hydroboration of a 1,3,7-triene homogeraniol. Org Synt 64:164-171

Lewis WJ, Nordlund DA (1984) Semiochemicals influencing fall armyworm parasitoid behaviour: implications for behavioural manipulation. Flor Entomol 67:343-349

Magalhães DM, Borges M, Laumann RA, Woodcock CM, Pickett JA, Birkett MA, Blassioli-Moraes MC (2016) Influence of two acylic homoterpenes (Tetranorterpenes) on the foraging behaviour of Anthonomus grandis Boh. J Chem Ecol 42:305-313

McCormick AC, Gershenzon J, Unsicker SB (2014) Little peaks with big effects: establishing the role of minor plant volatiles in plantinsect interactions. Plant Cell Environ 37:1836-1844

Michereff MFF, Laumann RA, Borges M, Michereff Filho M, Diniz IR, Farias Neto AL, Moraes MCB (2011) Volatiles mediating plantherbivory-natural enemy interaction in resistant and susceptible soybean cultivars. J Chem Ecol 37:273-285

Michereff MFF, Borges M, Laumann RA, Diniz IR, Moraes MCB (2013) Influence of volatile compounds from herbivore-damaged soybean plants on searching behavior of the egg parasitoid Telenomus podisi. Entomol Exp Appl 147:9-17

Michereff MFF, Borges M, Aquino MFS, Laumann RA, Gomes ACMM, Blassioli-Moraes MC (2016) The influence of volatile semiochemicals from stink bug eggs and oviposition-damaged plants on the foraging behaviour of the egg parasitoid Telenomus podisi. Bul Entomol Res 1:1-9

Midega CAO, Pittchar JO, Pickett JA, Hailu GW, Khan ZR (2018) A climate-adapted push-pull system effectively controls fall armyworm, Spodoptera frugiperda (J E Smith), in maize in East Africa. Crop Prot 105:10-15

Moraes MCB, Pareja M, Laumann RA, Hoffmann-Campo CB, Borges M (2008) Response of the parasitoid Telenomus podisi to induced volatiles from soybean damaged by stink bug herbivory and oviposition. J Plant Interac 3:1742-1756

Mumm R, Hilker M (2005) The significance of background odour for an egg parasitoid to detect plants with host eggs. Chem Senses 30:337-343

Mumm R, Schrank K, Wegener R, Schulz S, Hilker M (2003) Chemical analysis of volatiles emitted by Pinus sylvestris after induction by insect oviposition. J Chem Ecol 29:1235-1252

Nordlund DA, Lewis WJ, Gueldner RC (1983) Kairomones and their use for management of entomophagus insects. Response of
Telenomus remus to abdominal tips of Spodoptera frugiperda. $\mathbf{J}$ Chem Ecol 9:695-701

Peñaflor MFGV, Erb M, Miranda LA, Werneburg AG, Bento JMS (2011a) Herbivore-induced plant volatiles can serve as host location cues for a generalist and a specialist egg parasitoid. J Chem Ecol 37:1304-1313

Peñaflor MFGV, Erb M, Robert CAM, Miranda LA, Werneburg AG, Dossi FCA, Turlings TCJ, Bento JMS (2011b) Oviposition by a moth suppress constitutive and herbivore-induced plant volatiles in maize. Planta 234:207-215

Pickett JA, Khan ZR (2016) Plant volatile-mediated signalling and its application in agriculture: successes and challenges. New Phytol 212:856-870

Pickett JA, Woodcock CM, Midega CAO, Khan ZR (2014) Push-pull farming systems. Cur Opin Biotech 26:125-132

Pomari AF, Bueno AF, Bueno RCOF, Menezes AO Jr, Fonseca ACPF (2013) Releasing number of Telenomus remus (Nixon) (Hymenoptera: Platygastridae) against Spodoptera frugiperda Smith (Lepidoptera: Noctuidae) in corn, cotton and soybean. Ciência Rural 43:377-382

R Development Core Team (2009) R: A language and environment for statistical computing. Vienna: $\mathrm{R}$ foundation for statistical computing.

Ranum P, Peña-Rosas JP, Garcia-Casal MN (2014) Global maize production, utilization, and consumption. Ann NY Acad Sci 1312:105-112

Schmidt FGV, Monnerat R, Borges M, Carvalho R (2001) Criação de insetos para avaliação de agentes entomopatogênicos e semioquímicos. Circular Técnica - Embrapa Recursos Genéticos e Biotecnologia 21:20

Schröder R, Hilker M (2008) The relevance of background odor in resource location by insects: a behavioral approach. Bioscience 58:308-316

Silveira LCP, Vendramim JD, Rossetto CJ (1997) Efeito de genótipos de milho no desenvolvimento de Spodoptera frugiperda (J.E. Smith). An Soc Entomol Bras 26:291-298

Simpson M, Gurr GM, Simmons AT, Wratten SD, James DG, Leeson G, Nicol HI, Orre Gordon GUS (2011) Insect attraction to synthetic herbivore-induced plant volatile-treated field crops. Agric For Entomol 13:45-57

Steidle JLM, van Loon JJA (2003) Dietary specialization and infochemical use in carnivorous arthropods: testing a concept. Entomol Exp Appl 108:133-148

Tamiru A, Bruce TJA, Woodcock CM, Caulfield JC, Midega CAO, Ogol CKPO et al (2011) Maize landraces recruit egg and larval parasitoids in response to egg deposition by a herbivore. Ecol Lett 14:1075-1083

Toscano LC, Calado Filho GC, Cardoso AM, Maruyama WI, Tomquelski GV (2012) Impact of insecticides on Spodoptera frugiperda (Lepidoptera, Noctuidae) and its natural enemies on off-season maize in Cassilândia and Chapadão do Sul, State of Mato Grosso do Sul, Brazil. Arqu Inst Biol 79:223-231

Turlings TCJ, Erb M (2018) Tritrophic interactions mediated by herbivore induced plant volatiles: mechanisms, ecological, relevance, and application potential. Annu Rev Entomol 61:431-452

Turlings TCJ, Bernasconi M, Bertossa R, Bigler F, Caloz G, Dorn $S$ (1998) The induction of volatile emissions in maize by three herbivore species with different feedings habits: possible consequences for their natural enemies. Biol Cont 11:122-129

van Lenteren JC, Bueno VHP (2003) Augmentative biological control of arthropods in Latin America. Bio Control 48:123-139

Vet LEM, Dicke M (1992) Ecology of infochemical use by natural enemies in a tritrophic context. Ann Rev Entomol 37:141-172

Viana PA, Potenza MR (2000) Avaliação de antibiose e não-preferência em cultivares de milho selecionados com resistência à lagarta- docartucho. Bragantia 59:27-33 
Vieira CR, Blassioli-Moraes MC, Borges M, Pires CSS, Sujii ES, Laumann RA (2014) Field evaluation of (E)-2-hexenal efficacy for behavioral manipulation of egg parasitoids in soybean. Biocontrol 59:525-537

von Mérey G, Veyrat N, Mahuku G, Valdez RL, Turlings TCJ, D’Alessandro M (2011) Dispensing synthetic green leaf volatiles in maize fields increases the release sesquiterpene by the plants, but has little effect on the attraction of pest and beneficial insects. Phytochemistry $72: 1838-1847$

Wajnberg E (2006) Time allocation strategies in insect parasitoids: from ultimate to proximate behavioural mechanisms. Behav Ecol Sociobiol 60:589-611
Wäschke N, Meiners T, Rostás M (2013) Foraging strategies of parasitoids in complex chemical environments. In: Wajnberg E, Stefano $\mathrm{C}$ (eds) Chemical ecology of insect parasitoids, 1st edn. WileyBlackwell, UK, pp 37-63

Wojcik B, Whitcomb WH, Habeck DH (1976) Host range testing of Telenomus remus (Hymenoptera: Scelionidae). Fla Entomol 59:195-198 